\title{
Virtual Reality Analysis in Tennis Serve Technique Stability for Junior
}

\section{Masters}

Chuan Jia DU ${ }^{1, a}$, Ji He ZHOU ${ }^{1}$ and Shuai WANG ${ }^{1}$

Chengdu sport university, Chengdu, Sichuan, China

\begin{abstract}
This study consists of virtual reality analysis of tennis serve technique was constructed based on two male professional players from 2016 Chengdu ITF Junior Masters: Casper RUUD and Miomir Kecmanovic. The purpose of the study is to find an effective way of building stability of serves for junior players. This study will provide some considerable data for coaches and players in improving the stability and quality of the serve technique. Results of the study show 5 main points of view: (1) RUUD has a higher stability on controlling the height and location of serve. (2) During the swing stage, RUUD' s "scratching back" position of racket head is deeper, but Kecmanovic' s consistency is better. (3) For the consistency of the height to hit the ball, RUUD has a better control. (4) The height of the ball toss is a key point to affect the quality and stability for serves. (5) Overall, RUUD has a higher serve consistency than Kecmanovic.
\end{abstract}

\section{Introduction}

Stability in tennis means when a player produces a technique repeatedly, he or she shows the consistency of stroke power, impact direction, speed, and angles of joints for the certain tennis technique. The tennis serve is one of the most important techniques that initiates each point in a match. Developing high speed and consistency of serve percentage will make every professional tennis player more successful. However, usually when players cannot produce a high quality serve it is because the great pressure from serve makes bodies hardly work with neuromuscular system ideally. The consistency of swing power, impact direction, speed and angles of joints is stable or not can make a huge potential impact on serves.

This paper is a study that based on the sophisticated 3-D motion analysis system and the virtual reality tech to analyze the two players, Casper RUUD and Miomir Kecmanovic, specifically. Based on the study of the serve technique for these two players to provide recommendations for coaches and professional junior players about improving and strengthening tennis serve technique.

\footnotetext{
${ }^{a}$ Corresponding author: 549828421@qq.com
}

\section{Subjects and methods}

\subsection{Subjects}

The study sample included 2 male tennis players from 2016 Chengdu ITF Junior Masters: Casper $\bullet$ RUUD and Miomi $\bullet$ Kecmanovic. Table 1 is the information of these two players.

Table 1. Basic information of the subjects

\begin{tabular}{ccccc}
\hline Name & Height $(\mathrm{m})$ & DOB & Plays & Ranking \\
\hline RUUD & 1.83 & $12 / 22 / 1998$ & Right & 2 \\
Kecamanovic & 1.81 & $08 / 31 / 1999$ & Right & 8 \\
\hline
\end{tabular}

\subsection{Methods}

2.2.1 Three-dimensional video analysis: During 2016 Chengdu ITF Junior Masters, matches were recorded simultaneously with two high-definition digital JVC GC-PX10AC video cameras, recording at $50 \mathrm{fbS}$. The first camera was located in the back of the doubles sideline, and the second camera was located in the back 
of the base line. The angles of the two cameras were about $45^{\circ}$. (See Figure 1.) There were 10 first serves that be chosen randomly of each player, and then analyzed by the 3-D SignalTec software and Germany Dempster mannequin (16 links, 21 joints parameter). Due to the necessary of the study, the tennis ball and the racket head were also chosen as two parts of the test points. All the data were smoothed by the LPF method, and the cutting frequency was $8 \mathrm{~Hz}$.

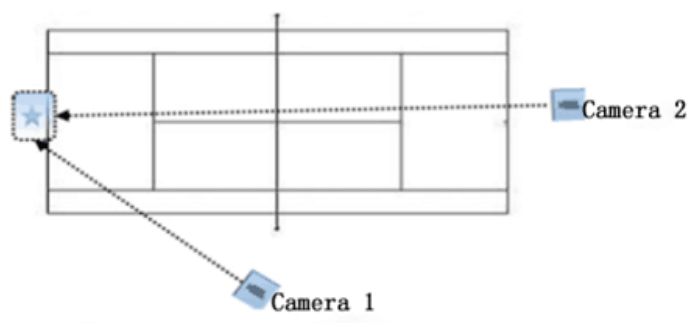

Figure 1. Diagram of cameras position

2.2.2 Three-dimensional virtual reality technology method: Based on the 3-D motion analysis, all the serve parameters of the two players were inputted into the virtual reality system, and analyzed by the 3-D animation motorically to analyze players' serves accurately.

2.2.3 Mathematical statistics: All the data were also analyzed by the spss19.0. The mean and standard deviation of the data can show the consistency and stability of the players

\section{Results}

\subsection{Stages of tennis serve and key parameters}

According to the feet stance, the serve technique has two different ways: Foot-back and Foot-up. Casper RUUD used Foot-up in the games, and Miomir Kecmanovic used Foot-back. For the study, the serve technique is divided into two stages as below and each part has different key parameters about the stability.

1) Ball toss stage: the moment to toss the ball and the maximum angle of knees flexion (lowest body center of gravity). Key parameters: the distance between the hand and the ball (vertical distance from the start of ball toss to the ground), the height of ball toss (vertical distance from the highest point of ball toss to the ground), the maximum angle of the right and left knee flexion.

2) Swing stage: the moment that knee flexion to the maximum, and the feet of the player has touched the ground after impact. Key parameters: The distance between the ground and the racket head when the racket was dropped behind individual' $\mathrm{s}$ head, the height of hitting the ball, and the time to finish the contact point part.

\subsection{Comparative analysis of the Ball Toss stage}

Ball toss means the player is going to release the tennis ball to make the toss to the proper location and height. Meanwhile, the racket hand and the body will move inversely. The muscle chain of the lower limbs begin to function in order to facilitate the stretch-shortening cycle that will contribute to storage of elastic potential energy in the muscles that are acting within the upper limb and lower limb muscle chain (Ellenbecker, Roetert, Bailie, Davies, \& Brown, 2002). In this stage, the location of the toss, the height of the toss, the maximum angle of knee flexion when the body center gravity is at the lowest, and etc. are all the important parameters of the quality for tennis serve technique. (See Table 2).

Table 2. Key Parameters of Ball Toss Phase

\begin{tabular}{ccccc}
\hline Name & $\begin{array}{c}\text { Location } \\
(\mathrm{m})\end{array}$ & $\begin{array}{c}\text { Height } \\
(\mathrm{m})\end{array}$ & $\begin{array}{c}\text { Left Knee } \\
\left({ }^{\circ}\right)\end{array}$ & $\begin{array}{c}\text { Right Knee } \\
\left({ }^{\circ}\right)\end{array}$ \\
\hline RUUD & $\mathbf{1 . 8 3 3} \pm \mathbf{0 . 0 4 0}$ & $\mathbf{3 . 2 1 5} \pm \mathbf{0 . 0 6 1}$ & $\mathbf{1 1 4 . 7} \pm \mathbf{4 . 5}$ & $\mathbf{1 1 9 . 2} \pm \mathbf{3 . 2}$ \\
Kecmanovic & $\mathbf{1 . 7 8 6} \pm \mathbf{0 . 0 8 3}$ & $\mathbf{3 . 3 8 2} \pm \mathbf{0 . 1 2 0}$ & $\mathbf{9 5 . 0} \pm \mathbf{4 . 8}$ & $\mathbf{1 2 6 . 5} \pm \mathbf{7 . 3}$ \\
\hline
\end{tabular}

All the data show that the average heights of toss location of RUUD and Kecmanovic are $1.833 \mathrm{~m}$ and $1.786 \mathrm{~m}$. The ratio of the location and their body height is 1.00 for RUUD, and 0.98 for Kecmanovic. According to the related research, the location of the toss should be the same height with the top of the player' $\mathrm{s}$ head, which means the ratio should be $1 \mathrm{(Hu}$ \& Wang, 2013). Therefore, RUUD' $s$ toss location is better than Kecmanovic. Kecmanovic' s toss location is $2 \%$ lower than the standard location. Besides, from the standard deviation of the toss location, RUUD has a higher ratio stability of toss location than Kecmanovic.

The toss height is the vertical distance from the highest toss point to the ground. It is an important parameter to affect serve technique. The higher the height of the toss, the faster will the ball be when it goes through the contact point. On the contrary, if the toss height is too low, the transaction between the ball toss stage and the swing stage will not be smooth. In conclusion, if a player can have a high ratio stability of the toss height, then he or she will control serve rhythm better. The means and standard deviations of the toss height of RUUD and Kecmanovic are $3.215 \mathrm{~m}, 3.382 \mathrm{~m}$, 0.061 and 0.120 . This shows that RUUD has a better control of the toss height. Comparing to RUUD, 
Kecmanovic has a lower toss location, which is $1.786 \mathrm{~m}$; but his toss height is $3.382 \mathrm{~m}$ that is higher than RUUD's. Kecmanovic's toss height standard deviation is 0.120 , which is also relatively large. The reason that Kecmanovic' $\mathrm{s}$ toss height stability is not as good as RUUD is because the force to the ball. When the location of the ball toss is too low, the player has to use a large force to the ball to make the impact. However, the large force will cause a large muzzle velocity, and at the same time the velocity works with the gravity, then the ball will uniform motion in a straight line (predict the force from the hand goes through the center of the ball). At that moment, it is hard for a player to control the force, so the height of toss could be too high and instable.

At the moment that the angle of knees flexion to the maximum, the average angles of RUUD' $s$ and Kecmanovic' $\mathrm{s}$ left and right knee joints flexion are $114.7^{\circ}, 119.2^{\circ} ; 95.0^{\circ}$, and $126.5^{\circ}$. According to related research, top tennis players' knee flexion of the opposite play hand is round $100^{\circ}$ ( $\mathrm{Hu} \&$ Wang). RUUD and Kecmanovic are both right handed players, so based on the angles of their left knees flexion, Kecmanovic has a larger angle. However, the reason that there is a big difference between the two players is because their stances are different. Kecmanovic uses the Foot-back stance so the angle between his legs is too large to make a big difference between the angles of his knees flexion. While RUUD uses the Foot-up stance to keep his knees flexion similarly. Therefore, because the difference of their stances, it is not reasonable to compare their knees flexion. The current \#1 ranking male tennis player, Novak Djokvoic, also uses the Foot-back stance to produce serves; and his minimum angle of knee flexion is $110.3^{\circ}$ (Yang \& Zhou, 2015). Therefore, Kecmanovic' s angle of knee flexion is too much to finish the following hitting process because the burden on the related muscle chain have a negative impact on the speed to stretch the extensor muscle group. Another top ranking player, Rafael Nadal, uses the Foot-up stance to serve, and the minimum angle of his left knee flexion is $109.3^{\circ}(\mathrm{Hu}$ \& Wang). This tell us that Ruud' s knee flexion angle is not large enough to stretch the extensor muscle group to storage the potential elastic energy.

\subsection{Comparative analysis of the Swing stage}

The swing part of the tennis serve is a complicated process to decided the quality of serve technique. When a player is ready to swing and hit the ball, his or her feet will bend first and then stretch fast. The racket head will not be swung up immediately but to be dropped down like "scratching back." The chest and the shoulder will form a big radian angle. The range of the "scratching back" position not only depends on the inertial of racket head, but also on the control of the position. The form of the "scratching back" position will produce a swing like whipping. At the contact point, the racket head will extend more through the contact zone to make the forearm do an internal rotation and then follow through to finish the serve. The key parameters of the swing stage are the height from the racket head to the ground of the "scratching back" position $\left(\mathrm{H}_{\mathrm{re}}\right)$, the height of the contact point $\left(\mathrm{H}_{\mathrm{cp}}\right)$, and the time to finish the contact point $\left(\mathrm{T}_{\mathrm{cp}}\right)$. (See Table 3).

Table 3. Comparison parameters in the swing stage

\begin{tabular}{cccc}
\hline Name & Hre $(\mathrm{m})$ & Hcp $(\mathrm{m})$ & Tcp $(\mathrm{s})$ \\
\hline RUUD & $1.068 \pm 0.072$ & $2.780 \pm 0.025$ & $0.11 \pm 0.02$ \\
Kecmanovic & $1.093 \pm 0.060$ & $2.821 \pm 0.041$ & $0.12 \pm 0.02$ \\
\hline
\end{tabular}

The range of the "scratching back" can be noticed from the distance between the racket head and the ground. The shorter the distance, the obvious the position, and vice versa. The mean heights of RUUD and Kecmanovic are $1.068 \mathrm{~m}$, and $1.093 \mathrm{~m}$; and the standard deviations are 0.072 and 0.060 . According to their mean and standard deviation, RUUD can form the position deeper, but Kecmanovic' $\mathrm{s}$ consistency is better.

After stretching the legs, the lower limbs are almost straight. At the moment that the two feet are off land, the racket head starts accelerating upward. The tennis ball will uniform linear motion from the highest point. When the ball falls to the contact point, the racket center should contact with the ball. The height of the contact point is the vertical distance from the racket to the ground. A proper height of the contact point will have a direct impact on hitting the ball. The average heights of the contact point of RUUD and Kecmanovic are $2.780 \mathrm{~m}$ and $2.821 \mathrm{~m}$; and the standard deviations are 0.025 and 0.041 . According to Yan and $\mathrm{Wu}$ 's study, the best ratio of the contact point height and a player' $\mathrm{s}$ height should be around 1.5 (Yan \& Wu, 2000). This ratio is 1.51 of RUUD, and 1.55 of Kecmanovic. Therefore, RUUD' $s$ height of contact point is better. Kecmanovic' s height of contact point is relatively high, so it will increase the instability to hit the ball. Besides, $\mathrm{Hu}$ and Wang also points out that the head between the highest ball toss point and the contact point should be around $0.5 \mathrm{~m}$ (Hu \& Wang). The mean head of RUUD is $0.435 \mathrm{~m}$, and of Kecmanovic is $0.561 \mathrm{~m}$. Both of them control the head within the effective head range. However, based on the free fall equation, the speed of 
the ball from Kecmanovic at the contact point is too fast, and this is a main reason that the standard deviation of his contact point height is relatively large.

The time to finish the contact point means the time that racket from the lowest point of the back to the contact point. It is an important parameter to evaluate the explosive power and motor coordination of swing stage. The mean time from the maximum knee flexion moment to contact point of RUUD and Kecmanovic is $0.11 \mathrm{~s}$ and $0.12 \mathrm{~s}$. There is not difference on the standard deviation for the two players, which is 0.02 . The lowest time that Nadal can finish is $0.066 \mathrm{~s}$ ( $\mathrm{Hu} \&$ Wang). Therefore, RUUD and Kecmanovic have to increase their muscle explosive power to shorten the time to finish the contact point and increase the speed to impact.

\section{Conclusion}

1) The mean heights of ball toss location for RUUD and Kecmanovic are $1.833 \mathrm{~m}$ and $1.786 \mathrm{~m}$. This shows that RUUD has a proper height of toss location, but Kecmanovic's toss location is relatively low. The standard deviations for RUUD and Kecmanovic are 0.040 and 0.083 , which means RUUD has a higher ratio of stability of toss location.

2) The mean ball toss heights of RUUD and Kecmanovic are $3.215 \mathrm{~m}$ and $3.382 \mathrm{~m}$, which means RUUD can control the height more ideally. The standard deviations are 0.061 and 0.120 , so RUUD's stability of toss heights is also better.

3) The mean angles of the maximum knee flexion for RUUD and Kecmanovic are $114.7^{\circ}$ and $95.0^{\circ}$. Therefore, the angle of Kecmanovic is too much, and the angle of RUUD is too small. The standard deviations are 4.5 and 4.8 , so both of them have a relative high consistency on controlling the angles of knee flexion.

4) When RUUD and Kecmanovic are forming the "scratching back" position, the mean heights from racket head to the ground are $1.068 \mathrm{~m}$ and $1.093 \mathrm{~m}$, and the standard deviations are 0.072 and 0.060 . Therefore,
RUUD can make the position deeper but Kecmanovic has a higher ratio stability of this position.

5) RUUD has a better control on the contact point height. The height of the ball toss is a key point to affect the stability of the height of the contact point.

6) There is no difference between RUUD and Kecmanovic on the time to finish the contact point. However, comparing to the top ranking player, Nadal, RUUD and Kecmanovic still spend too much time to impact in a high speed.

7) Overall, RUUD has a higher serve technique consistency.

\section{References}

1. David Whiteside, Bruce Clifford Elliott. Coordination and variability in the elite female tennis serve[J].Journal of Sports Sciences; 2015, 33 (7): 675-686.

2. Zhilei Wang,ShanfeiZhang. Kinematic Analysis on the Serve Technique of lower limbs[J]. Journal of ningbo university of technology. 2009,21(3):77-80.

3. Ellenbecker, T. S., Roetert, E.P., Bailie, D.S., Davies, G.J., \& Brown, S.W.Glenohumeral joint total rotation range of motion in elite tennis players and baseball pitchers. Medicine and Science in Sports and Exercise; 2002, 34(12): 2052-2056.

4. Chuanjia Du,Jihe Zhou,Shuai Wang. Kinematic Analysis on the Serve Technique of Elite Tennis Player. Grigor - Dimitrov Based on $3 D$ VR Technology[J]. MATEC Web of conferences, 2016, 44.

5. Botao Yan,Yanxi Wu. Biomechanical analysis of the tennis serve[J]. Journal of Sports science. 2000, 20 (4): 80-84.

6. Kai Hu,Yun Wang. Serve action analysis of the Elite male tennis players[J].Journal of Sports research and education: 104-106. 